\title{
Body Mass Index and Waist Hip Ratio a Predictor of Hypertension of Adolescent Boys and Girls in a Metropolitan City in Bangladesh
}

\author{
MAKTHER $^{\mathrm{a}}$, MS TABREZ $^{\mathrm{b}}, \mathrm{H}_{\mathrm{AKTHER}}^{\mathrm{c}}, \mathrm{ST}^{\mathrm{A}}$ ALAM $^{\mathrm{d}}$, MH SUMON $^{\mathrm{e}}$
}

\begin{abstract}
Summary:
Background: The associations between elevated blood pressure and overweight increasing now a days. Over the last few decades the prevalence of elevated blood pressure also increased in children due to increasing pediatric overweight because of changing dietary habits, changing pattern of life style.

Objective: To see the body mass index and waist hip ratio a predictor of hypertension of adolescent boys and girls in a metropolitan city in Bangladesh.

Methods and Materials: This cross-sectional-descriptive study was conducted in the department of Pediatrics, Sylhet M.A.G. Osmani Medical College Hospital, Sylhet during the period from January 2014 to June 2014. Adolescent boys and girls in Sylhet Metropolitan City were included according to inclusion and exclusion criteria. Inclusion criteria were children aged 12-16 years in Sylhet Metropolitan City. Children aged under 12 or above 16 years and with any systemic disorder were excluded.
\end{abstract}

Introduction:

Elevated blood pressure (BP) contributes to the global disease burden worldwide and accounts for 7 million

a. Dr. Mahboba Akther, Resident, Phase B, Department of Neonatology, Bangabandhu Sheikh Mujib Medical University (BSMMU), Dhaka.

b. Dr. Md. Shahjada Tabrez, Medical Officer, National Institute of Diseases of the Chest and Hospital (NIDCH), Dhaka

c. Dr. Habiba Akther, Associate professor (CC), Department of Gynae and Obstetrics, North East Medical College, Sylhet.

d. Dr. Syeda Tabassum Alam, Associate Professor, Department of Paediatric Neurology,BSMMU, Dhaka, Bangladesh.

e. Dr. Md Hanif Sumon, Resident, Phase B Department of Neonatology, Bangabandhu Sheikh Mujib Medical University, Shahbagh, Dhaka

Address of Correspondence: Dr. Mahboba Akther, Resident, Phase B, Department of Neonatology, Bangabandhu Sheikh Mujib Medical University (BSMMU), Dhaka. Contact no: 01937401200 E-mail: mahbobaakther83@gmail.com

Received: 6 July, 2019

Accepted: 18 March, 2020
Results: This study showed that $56.4 \%$ adolescents were male and $43.6 \%$ were female with ratio of male: female $=1.3: 1$ and their average age was $14 \pm 2$ yrs. Average height of male was $154.82 \pm 49.08 \mathrm{~cm}$ and female was $148.42 \pm 38.09 \mathrm{~cm}$. Average weight of male was $49.12 \pm 10.49 \mathrm{~kg}$ and that of female was $44.48 \pm 12.08 \mathrm{~kg}$.Prevalence of hypertension in adolescent boys and girls of Sylhet city was $0.70 \%$ and there was a significant relationship of hypertension with the obesity. Among 7 (seven) hypertensive children, 3(42.8\%) were overweight and $3(42.8 \%)$ obese $(p=0.001)$. While waist hip ratio among those, $2(28.6 \%)$ were excellent and $5(71.4 \%)$ were average; was not significant $(p=0.745)$ among the hypertensive adolescents.

Conclusion: Prevalence of hypertension in apparently healthy adolescent child of Sylhet city was $0.70 \%$ and had a strong relationship with high body mass index.

Key words: Hypertension, body mass index, essential hypertension

(J Bangladesh Coll Phys Surg 2020; 38: 110-115) DOI: https://doi.org/10.3329/jbcps.v38i3.47057

deaths each year. ${ }^{1}$ The prevalence of childhood overweight has increased markedly over the last two decades. Evidence suggests that pediatric hypertension may also have become more prevalent than previously reported ${ }^{2}$. This increase reflects an epidemiologic shift from secondary hypertension (most often caused by renal disease) to primary (i.e essential) hypertension as the main cause of hypertension in the pediatric age range .Primary hypertension.

In children has become increasingly common in association with other cardiovascular risk factors that include overweight, insulin resistance, and dyslipidemia .The association between overweight and hypertension in children has been reported in a variety of ethnic and racial groups, with virtually all studies finding higher blood pressures and/or higher prevalence of hypertension in overweight compared with lean children. ${ }^{3}$ 
Various factors are known to influence onset of this essential hypertension in childhood. Factors known to affect blood pressure among children include age, sex, body size, race/ethnicity, obesity, familial aggregation and socioeconomic status. ${ }^{4}$ Some studies have shown that obesity defined as body mass index(BMI) of e"95 percentile based on gender and age does not correlate well with body fat distribution as compared with waist circumference (WC) which is more accurate in predicting abdominal girth, thus correlating better with hypertension in children. Approximately $20 \%$ of American youth are obese, and up to $10 \%$ of obese youth have hypertension. ${ }^{5}$

As blood pressure (BP) in children, tends to track from childhood into adulthood, and prevention and control of elevated blood pressure in children might be an important strategy for limiting the global disease burden due to hypertension. ${ }^{6}$ The development of such a strategy, however, requires more evidence for the relation between blood pressure and its associated factors in children of different populations, particularly in a context of a changing epidemic of pediatric obesity.7

With globalization bringing more lifestyle modifications, adolescents are exposed to multiple risk factors including obesity and also family history of hypertension. 8 Research in this area will help policy makers to see if there is a need for addressing this problem effectively in prevention and management of hypertension in children and adolescents. Early diagnosis of hypertension is an important strategy in its control, which was useful in tracking and effective treatment and to prevent further complications. So the objective of this study was to see the body mass index and waist hip ratio a predictor of hypertension of adolescent boys and girls in a metropolitan city in Bangladesh.

\section{Methods}

This cross-sectional - descriptive study was conducted in the Department of Paediatrics, Sylhet M.A.G. Osmani Medical College Hospital, Sylhet from January 2014 to June 2014 after approval of Ethical Committee of Sylhet M.A.G. Osmani Medical College Hospital, Sylhet. Children aged 12-16 years in Sylhet Metropolitan City were selected. Children who were suffering from chronic systemic disorder were excluded from the study. Sample size was 1000 calculated using Cochran's formula $\left[\mathrm{n}=\mathrm{z}^{2} \mathrm{pq} / \mathrm{d}^{2}\right]$ considering $1 \%$ level of significance, $1 \%$ precision level (marginal error).

Eight geo-political wards were selected from 27 wards of Sylhet city corporation by lottery. One secondary school was selected from schools in each of the selected wards by lottery. Then 125 children from each school ( 25 from each class) were selected by purposive sampling method. Authority of the school (principals or head master) was explained about purpose of the study. They had complete freedom to withdraw themselves from the study at any stage. When they were fully convinced only then written informed consent was taken.

A structured questionnaire was filled up through face to face interview at the beginning of the study. The exact age of children was verified from school records. The blood pressure, height, and weight of each student was measured by the researcher herself. Children those who had positive family history of hypertension, was confirmed by telephonic interview of parents. Students, those who had systemic illness (such as Acute glomerulonephritis, Nephrotic syndrome) were excluded by details history and thorough physical examination.

It was taken at morning before the starting of school. At a time 10 students was taken to a room and was allowed to sit for 10 minutes. Meanwhile, in order to make them relaxed the purpose and procedure of the study was explained to them. Weight of students was measured sensitive to $0.1 \mathrm{~kg}$ after removing shoes but not removing the uniform (due to privacy problem) by bathroom scale and height sensitive to $0.1 \mathrm{~cm}$ by height scale. Hip (start at one hip and wrap the tape around the other hip and back to where started) and waist circumference (start at the top of hip bone, then bring the tape measured all the way around body) was measured using flexible measuring tape. Body mass index and waist-hip ratio was calculated.

After that blood pressure was recorded one by one. The resting pulse rate (PR), Systolic blood pressure (SBP) and Diastolic blood pressure (DBP) was measured by mercury sphygmomanometer using the same machine throughout the study. Age appropriate cuff covering $2 / 3 \mathrm{rd}$ of the length of the arm was measured in right arm, in sitting posture with a back rest, with cubital fossae at the level of heart. The bladder 
of the cuff was inflated to about $200 \mathrm{~mm} \mathrm{Hg}$ level, then it was deflated slowly at a rate of $1 \mathrm{~mm}$ per second. Systolic blood pressure was measured at the level of first appearance of sound (Korotkoff phase 1) and diastolic blood pressure was measured at the level of muffling of sound (Korotkoff phase V). Readings was taken for three times at an interval of one minutes. All these three readings was recorded and their average was considered as the blood pressure of that child at that time. Children whose blood pressure was found above $95^{\text {th }}$ percentile for age and sex was measured for the second time after two weeks. Children whose blood pressure was again found above $95^{\text {th }}$ centile was measured for the third time after two weeks. Those children having blood pressure above $95^{\text {th }}$ percentile on three occasions was identified to have hypertension. Weight of students was measured sensitive to $0.1 \mathrm{~kg}$ after removing shoes and school uniforms by bathroom scale and height sensitive to $0.1 \mathrm{~cm}$ by height scale. Hip and waist circumference was measured using measuring tape. Body mass index was measured by weight in $\mathrm{kg}$ divided by height in $\mathrm{m}^{2}$ and waist-hip ratio was calculated.

Those who was identified to have hypertension, was referred to hospital for further evaluation to find out the cause of hypertension, either primary or secondary and risk factors by details history, thorough physical examination and laboratory investigation ( Random blood sugar, Lipid profile, Serum creatinine, Chest Xray, Electrocardiogram, Echocardiogram, Ultrasonography of whole abdomen and Urine $\mathrm{R} / \mathrm{M} / \mathrm{E}$ ).

Relevant data was recorded in predesigned questionnaire. Data was processed manually and analyzed with the help of SPSS (Statistical package for social sciences) Version 21.0. Quantitative data was expressed as mean and standard deviation. Qualitative data was expressed as frequency and percentage.

\section{Results:}

During the study period total 1000 adolescents were enrolled in this study. $56.4 \%$ respondents were male and $43.6 \%$ were female with ratio of male: female $=1.3: 1$ and their average age was $14 \pm 2 \mathrm{yrs}$. Average height of male was $154.82 \pm 49.08 \mathrm{~cm}$ and female $148.42 \pm 38.09 \mathrm{~cm}$. Average weight of male was $49.12 \pm 10.49 \mathrm{~kg}$ and that of female was $44.48 \pm 12.08 \mathrm{~kg}$.(Table-I). Table II shows $32.3 \%$ were underweight, $56.9 \%$ were normal weight, $8.7 \%$ were overweight and $2.1 \%$ obese. Among the respondents hip circumference in male was $72.67 \mathrm{~cm}$ and in female was $78.70 \mathrm{~cm}$. Average waist circumference of male was $67.70 \mathrm{~cm}$ and that of female was $68.86 \mathrm{~cm}$.(Table-III). Table IV shows maximum $(59.2 \%)$ respondents had average waist hip ratio of 0.90 0.95 , among them male female ratio was $1.5: 1$, followed by $36.8 \%$ had $<0.85$ waist hip ratio and only $4 \%$ had $>0.95$ waist hip ratio.

\section{Table-I}

Baseline characteristics of the study populations

$$
(N=1000)
$$

\begin{tabular}{|c|c|c|c|}
\hline Characteristics & Frequency & Percent & Mean \pm SD \\
\hline \multirow[t]{2}{*}{ Sex } & Male -564 & & \\
\hline & Female -436 & & \\
\hline \multirow[t]{2}{*}{ Age( years) } & Male & & $14 \pm 2$ \\
\hline & Female & & \\
\hline \multirow[t]{2}{*}{ Height(cm) } & Male & & $154.82 \pm 49.08$ \\
\hline & Female & & $148.42 \pm 38.09$ \\
\hline \multirow[t]{2}{*}{ Weight(kg) } & Male & & $49.12 \pm 10.49$ \\
\hline & Female & & $44.48 \pm 12.08$ \\
\hline Total & 1000 & 100 & \\
\hline
\end{tabular}

Table-II

Body Mass Index of the study populations $(N=$ 1000)

\begin{tabular}{|c|c|c|c|}
\hline BMI & Sex & Frequency & Percent \\
\hline Underweight & Male - 179 & & \\
\hline$(<18.5)$ & Female-144 & 323 & 32.3 \\
\hline Normal & Male- 323 & & \\
\hline$(18.5-24.99)$ & Female- 246 & 569 & 56.9 \\
\hline Overweight & Male- 49 & & \\
\hline$(25-29.99)$ & Female- 38 & 87 & 8.7 \\
\hline Obese & Male- 13 & & \\
\hline$(\geq 30)$ & Female- 8 & 21 & 2.1 \\
\hline Total & & 1000 & 100 \\
\hline
\end{tabular}


Table-III

Hip and waist circumference of the study populations $(N=1000)$

\begin{tabular}{llcc} 
Parameter & Sex & Frequency & Mean \pm SD \\
\hline Hip circumference & Male & 564 & $72.67 \pm 14.4078 .70 \pm 14.20$ \\
& Female & 436 & $67.70 \pm 13.4368 .86 \pm 12.46$ \\
Normal(18.5-24.99) & Male & 564 & \\
& Female & 436 & \\
\hline Total & & 1000 & \\
\hline
\end{tabular}

Table IV

\begin{tabular}{|c|c|c|c|c|}
\hline \multicolumn{5}{|c|}{ Waist hip ratio of the study populations $(N=1000)$} \\
\hline Waist hip ratio & Sex & Frequency & Percent & Mean \pm SD \\
\hline \multirow[t]{2}{*}{$<0.85$ (Excellent) } & Male-164 & & & \\
\hline & Female-204 & 368 & 36.8 & \\
\hline \multirow[t]{2}{*}{$0.85-0.89(\mathrm{Good})$} & Male-0 & & & \\
\hline & Female-0 & 00 & 00 & $0.86 \pm 0.06$ \\
\hline \multirow[t]{2}{*}{$0.90-0.95$ (Average) } & Male-372 & & & \\
\hline & Female-220 & 592 & 59.2 & \\
\hline \multirow[t]{2}{*}{$>0.95$ (At risk) } & Male-28 & & & \\
\hline & Female-12 & 40 & 4.0 & \\
\hline Total & & 1000 & 100 & \\
\hline
\end{tabular}

Table V

Prevalence of hypertension $(N=1000)$

\begin{tabular}{lcc} 
Hypertension & Frequency & Percent \\
\hline Yes & 7 & 0.7 \\
No & 993 & 99.3 \\
\hline Total & 1000 & 100.0 \\
\hline
\end{tabular}

This study showed that prevalence of hypertension among the study population 0.7 . It was observed that those who were overweight and obese, were at risk of hypertension. The difference was statistically significant $(\mathrm{P}=0.001)$. (Table VI). Among the hypertensive adolescents there was no significant association found between hypertension and waist hip ratio $(\mathrm{P}>0.05)$ (TableVII).

Table VI

\begin{tabular}{|c|c|c|c|c|c|}
\hline \multicolumn{6}{|c|}{ Association between hypertension and Body Mass Index $(N=7)$} \\
\hline \multirow[t]{3}{*}{$\mathrm{BMI}$} & \multicolumn{4}{|c|}{ Hypertension } & \multirow[t]{3}{*}{ P value } \\
\hline & \multicolumn{2}{|c|}{ Yes } & \multicolumn{2}{|c|}{ No } & \\
\hline & Frequency & Percent & Frequency & Percent & \\
\hline Underweight & 0 & 0 & 323 & 32.5 & \\
\hline Normal & 1 & 14.4 & 566 & 57.0 & \\
\hline Overweight & 3 & 42.8 & 84 & 8.5 & 0.001 \\
\hline Obese & 3 & 42.8 & 20 & 2.0 & \\
\hline Total & 7 & 100 & 993 & 100 & \\
\hline
\end{tabular}


Table VII

\begin{tabular}{|c|c|c|c|c|c|}
\hline \multicolumn{6}{|c|}{ Association between hypertension and waist hip ratio $(N=7)$} \\
\hline \multirow[t]{3}{*}{ Waist hip ratio } & \multicolumn{4}{|c|}{ Hypertension } & \multirow[t]{3}{*}{ P value } \\
\hline & \multicolumn{2}{|c|}{ Yes } & \multicolumn{2}{|c|}{ No } & \\
\hline & Frequency & Percent & Frequency & Percent & \\
\hline$<0.85$ (Excellent) & 2 & 28.6 & 366 & 36.9 & \\
\hline $0.85-0.89$ (Good) & 0 & 00 & 0 & 00 & \\
\hline 0.90-0.95 (Average) & 5 & 71.4 & 587 & 59 & 0.745 \\
\hline$>0.95$ (At risks) & 0 & 00 & 40 & 4.0 & \\
\hline Total & 7 & 100 & 993 & 100 & \\
\hline
\end{tabular}

\section{Discussion}

Hypertension is a disease with a high morbidity and mortality. A silent threat to the health of people all over the world is hypertension. It is suggested that hypertension has its origin in childhood but goes undetected unless not followed up carefully during this period. Early identification of children at risk for hypertension, proper evaluation and appropriate management are important to prevent the serious and long term complications associated with the condition. The present study was undertaken to see the predictability of BMI and west hip ratio of hypertension.

Prevalence of hypertension in this study population was $0.7 \% .{ }^{9}$ Kumar CK found that prevalence of hypertension is $2 \%$ to $5 \% .{ }^{9}$ There was no age or sex predilection in this study. In a similar study, Suphi et al. ${ }^{10}$ found no sex differences in the prevalence of hypertension but average blood pressure values (systolic/diastolic/mean) increases with age.

There was an overwhelming evidence in this study that the prevalence of hypertension was high among obese individuals $(\mathrm{p}=0.001)$, which is highly significant. Jonathan et al. ${ }^{11}$ also found obesity and overweight a major risk factors for hypertension. Hall $\mathrm{JE}^{12}$ also showed similar finding that chronic obesity also causes marked structural changes in the kidneys that eventually leads to a loss of nephron function, further increasing the arterial pressure.

This study results also coincides with an Indian study done by Goel R et al. ${ }^{13}$ in Delhi among school children, published in 2010. Anand et al. ${ }^{14}$ also found that compared to their normal counterparts, prevalence of hypertension was 15 times more in obese children. Sorof et al. ${ }^{15}$ also showed more prevalence of hypertension in obese children as compared to non-obese (33\% vs $11 \%$ ).In this study, among 1000 respondents, $32.3 \%$ were underweight, $56.9 \%$ were normal weight, $8.7 \%$ were overweight and $2.1 \%$ obese .Prevalence of hypertension was high among obese individuals ( $\mathrm{p}=0.001$ ), which is highly significant. This also confirms results of done by Jonathan et al. ${ }^{11}$ Sorof et al. ${ }^{15}$ also showed more prevalence of hypertension in obese children as compared to non-obese ( $33 \%$ vs $11 \%$ ).

This study found average hip circumference was 78.70 $\mathrm{cm}$ and average waist circumference was $67.70 \mathrm{~cm}$. Waist hip ratio of maximum respondents (59.2\%) were 0.90$0.95,36.8 \%$ were $<0.85$ and only $4 \%$ were at risk that means, $>0.95$. So, statistically this study could not find any significant association between waist hip ratio and hypertension though there is strong evidence in this study that obesity and overweight among males with waist-hip ratio more than normal is highly significant for higher prevalence of adolescent hypertension. This results agrees with similar finding of Goel $\mathrm{R}$ et al.13done in Delhi.

This study shows all positive hypertension respondents had normal ultrasonography, chest x-ray and echocardiogram. Electrocardiogram has shown $85.7 \%$ were normal and $14.3 \%$ were found left ventricular hyperplasia. Urine $\mathrm{R} / \mathrm{M} / \mathrm{E}$ of all respondents were normal. Regarding lipid profile, cholesterol mean $\pm \mathrm{SD}$ was $171.00 \pm 38.78$, TG mean \pm SD was $92.28 \pm 30.72$, HDL mean \pm SD was $52.71 \pm 22.05$ and LDL mean \pm SD was $86.00 \pm 13.84$. Serum creatinine level was $0.83 \pm 0.15$ and 
random blood sugar level was $8.43 \pm 2.05$. Thus, investigations of these hypertensive children failed to document any underlying cause. Similar opinion is experienced by Londe $\mathrm{S}$ et al ${ }^{16}$. This study indicated that association between abnormal lipid profile and hypertension in children were not statistically significant.

\section{Conclusion:}

A group of adolescence aging 12-16 years in metropolitan city was studied to see prevalence of hypertension. Their waist hip ratio and body mass index (BMI) was determined and correlated with the prevalence of Hypertension. Prevalence of hypertension in apparently healthy adolescent child of Sylhet city was $0.70 \%$ and had a strong relationship with high body mass index.

\section{Limitations of the study}

- This study was conducted in only Sylhet city and may not reflect exact situation of rural area of Sylhet.

- This was a cross-sectional and descriptive study with small sample size.

- All measurements were made by single observer.

\section{Recommendations}

These asymptomatic children with essential hypertension may become adult symptomatic patients. So, blood pressure should be measured for all children during routine school health checkup.

\section{References}

1. Yusuf S, Reddy S, Ounpuu S, Anand S. Global burden ofcardiovascular diseases: part I-general considerations, the epidemiologic transition, risk factors, and impact of urbanization. Circulation 2001; 104: 2746-2753

2. Ogden CL, Troiano RP, Briefel RR, Kuczmarski RJ, Flegal KM, JohnsonCL. Prevalence of overweight among preschool children in the United States, 1971 through 1994. Pediatrics 1997; 99(4)

3. Jonathan M. Sorof MD, Dejian L. Overweight, Ethnicity, and the Prevalence of Hypertension in School-Aged Children .J PEDIATR 2004; 113(3):475-482
4. Choy CS, Huang YK, Liu YH, Yang C, Liao CC, Li JS, et al. Waist circumference as a predictor of pediatric hypertension among normal-weight Taiwanese children. J Exp Clin Med 2011; 3:34-39

5. Sundar JS, Adaikalam JMS, Parameswari S, Valarmarthi S, Kalpana S, Shantharam D. Prevalence and Determinants of Hypertension among Urban School Children in the Age Group of 13- 17 Years in, Chennai, Tamilnadu. Epidemiol 2013; 3(3): 130

6. Whitlock EP, Williams SB, Gold R, Smith PR, Shipman SA. Screening and interventions for childhood overweight: a summary of evidence for the US Preventive Services Task Force. Pediatrics 2005; 116:e125-e144

7. Lane DA, Gill P. Ethnicity and tracking blood pressure in children. J Human Hypertension 2004; 18:223-228

8. National Heart, Lung and Blood Institute Joint National Committee on Prevention, Detection, Evaluation and Treatment of High Blood Pressure. The Seventh Report of the Joint National Committee on prevention, detection, evaluation and treatment of high blood pressure: The Seventh Report of the Joint National Committee on prevention, detection, evaluation and treatment of high blood pressure. The JNC 7 report. JAMA 2003; 289: 2560 2572

9. Kumar CK, Christy A, Kumar G, Kumar RV, Srikumar R, Gobi VV. Prevalence of Hypertension among School Children in Puducherry. International Journal of Innovative Research \& Development 2014; 3(4):127-132

10. SuphiMD.Blood pressure profiles and hypertension in Iraqi primary school children.Saudi Med J. 2006; 27:482-486.

11. Jonathan M. Sorof MD, Dejian L. Overweight, Ethnicity, and the Prevalence of Hypertension in School-Aged Children .J PEDIATR 2004; 113(3):475-482

12. Hall JE. The kidney, hypertension and obesity. American Heart Association. Hypertension 2003; 41:625-633

13. Goel R, Misra A, Agarwal SK, Vikram N.Correlates of hypertension among urban Asian Indian adolescents. Arch Dis Child 2010; 95: 992-997

14. Anand NK, Lalit T. Prevalence of Hypertension in school going children. Ind Pediatr 1996; 33:377-381

15. Sorof JM, Lai D, Turner J, Poffenbarger T, Portman RJ. Overweight, ethnicity, and the prevalence of hypertension in school-aged children. Pediatrics 2004; 113:475-482

16. Londe S, Bourgoigine JJ, Robson AM. Hypertension in apparently normal children. J Pediatr 1971; 78: 569-577 